\title{
Epistemologia da Ciência da Informação: objeto de estudo e principais categorias ${ }^{1}$
}

Epistemology of Information Science: object of study and main categories

$\begin{array}{r}\text { Miguel Ángel Rendón-Rojas } \\ \text { Doutor em Filosofia pela Universidade Estatal de Moscou "M.V. Lomonósov". } \\ \text { Pesquisador do Centro Universitario de Investigaciones Bibliotecológicas da Universidade Nacional Autónoma do } \\ \text { México. }\end{array}$
E-mail: $\underline{\text { marr@unam.mx }}$

\section{Pressupostos Epistemológicos}

Em nossa discussão sobre o assunto partimos de algumas ideias que acreditamos já terem sido tratadas anteriormente e foram aceitas e devidamente fundamentadas.

I. Necessidade e importância de uma pesquisa epistemológica.

Em um trabalho anterior mostramos que a pesquisa epistemológica da Ciência da Informação é importante e necessária em quanto ajude na busca de identidade à disciplina, possibilite escolher uns fundamentos meta-teóricos para o desenvolvimento superior desta, e proporcione as condições necessárias para a existência da multidisciplinaridade e interdisciplinaridade sem perder a identidade. (RENDÓN-ROJAS, 2008)

\section{Ciência}

O conhecimento de ciência que temos está longe do modelo positivista que se tem dela. Por um lado, num sentido negativo podemos dizer que a ciência:

a) Não utiliza apenas um método que é de carácter empírico-experimental, matemático e lógico,

b) Não existem somente ciências nomológicas que descobrem leis,

c) Não têm apenas a função de explicar e prever, ou seja, manipular a realidade,

d) A existência de um só paradigma aceito por toda a comunidade científica para que se obtenha a ciência, não é uma condição necessária.

\footnotetext{
${ }^{1}$ Proyecto PAPIIT IN 401311
}

InCID: R. Ci. Inf. e Doc., Ribeirão Preto, v. 3, n. 1, p. 3-14, jan./jun. 2012. 
Por outro lado, num sentido positivo, afirmamos que a ciência:
a) Utiliza uma metodologia que admite una extensão de métodos,
b) Também cumpre outra função epistemológica que é a compressão da realidade,
c) Dentro de uma mesma comunidade científica coexistem diferentes enfoques, escolas, propostas,
d) Possui um objeto de estudo,
e) Possui um dispositivo teórico que inclui conceitos, categorias, enunciados, teorias.

\section{Discussão Sobre o Objeto de Estudo da Ciência da Informação}

Assim, levando em consideração que uma das características da ciência é que ela tem um objeto de estudo, alguns pesquisadores da área de Ibero-américa decidiram realizar um trabalho de pesquisa com o título 'Uma análise teórico-epistemológica da Documentação e estudos da informação. Unidade na diversidade: Documentação e Ciência da Informação', no qual um dos objetivos era refletir sobre o objeto de estudo da Ciência da Informação, ou como se diz na Espanha, Documentação; ou como é conhecida no México, Biblioteconomia.

Posto que os resultados desta análise e discussão sobre o objeto de estudo da disciplina informativo documental serão publicados, a continuação apresentou alguns avanços das propostas que alguns pesquisadores expuseram a respeito.

\section{A. A teoria comunicativa da Biblioteconomia/Documentação (José López Yepes. Espanha.)}

Para o Doutor José López Yepes, a Biblioteconomia ou Documentação possui uma característica essencial que consiste em que além de ser una ciência social, é informativocomunicativa, a qual tem como objeto de estudo um processo informativo que gera informação documental. Este processo inclui a retenção, recuperação e transformação de mensagens produzidas em processos informativos anteriores, e se comunicam transformados como fontes de informação. (LÓPEZ YEPES, 2011) 
Desta maneira, como podemos observar, a ênfase está na ação comunicativa que possui esse processo informativo. A razão de ser de todo esse processo é a comunicação.

B. Os processos de mediação do conhecimento como elementos integradores - unificadores do discurso epistemológico das ciências da informação. (Francys Delgado y Johan Pirela. Venezuela)

Enquanto isso, os Doutores Delgados e Pirela, da Universidade de Zulia, propõem os processos de mediação do conhecimento como elementos integradores - unificadores do discurso epistemológico das ciências da informação, já que tais processos constituem os componentes medulares da ação das bibliotecas, arquivos, centros de informação e documentação, em cujos espaços se definem e planificam estratégias para aproximar mundo da produção informativa e documental com o mundo de quem precise da informação para usá-la na vida acadêmicoprofissional e na pessoal-social, e essa aproximação envolve processos complexos de mediadores orientados pela interiorização-reconstrução de significados e geração de mensagens. (DELGADO; PIRELA, 2011).

C. A intervenção (específica) que é realizada sobre a informação. (Cristina Ortega Dotta. Brasil)

A Doutora Cristina Ortega da Universidade de Minas Gerais afirma que as necessidades de informação, abordadas quanto aos modos e meios de satisfazê-las, e as motivações e implicações dos mesmos, são o fenômeno propulsor da área. O objeto da Ciência da Informação então é a intervenção (específica) que é realizada sobre a informação, por meio da elaboração de registros ou inscrições, visando possibilitar permanência e acesso para usos posteriores. (ORTEGA, 2011)

A área estuda as ações intencionalmente realizadas com o fim de promover o uso qualificado da informação. Pode-se dizer que estas ações estão voltadas a aguçar ou potencializar nas pessoas percepções sobre os objetos do mundo. Trata-se de objetos transformados em documentos, de tal modo que a função da área pode ser definida como a de construir documentos, visando realizar a mediação entre objetos potencialmente informativos e pessoas potencialmente 
usuárias da informação.

D. A organização documental como eixe identificador e objeto de estudo das áreas da informação documental. (Natalia Quintero. Colombia)

Do ponto de vista da Doutora Natalia Quintero da Universidade de Antioquia, a organização documental é o processo básico que permite o acesso, o uso e a aplicação social da informação nas comunidades de usuários, os cidadãos ou a sociedade em geral. O processo de organização documental "relaciona os produtos intelectuais e informacionais de algumas pessoas com a necessidade intelectual e informacional de outras, geralmente distantes em espaço e tempo" (SERRAI, 1982); o qual é possível utilizando o método e as estratégias bibliográficas para identificar e conectar o conteúdo dos documentos, analisar a informação, descrevê-la, classificá-la, catalogá-la, indexá-la, conservá-la e valorizá-la, com a finalidade essencial da sua recuperação e uso posterior por parte dos usuários.

A organização documental possui dois âmbitos de ação. O primeiro refere-se ao processo compreensivo, lógico, linguístico, categorial dos documentos que os profissionais realizam da área na entidade informativa documental. Neste sentido, aplicam-se conhecimentos das áreas da linguística, lógica e pesquisa científica para realizar os processos de classificação, como operação cognitiva e intelectual, para agrupar, relacionar e diferenciar um conjunto de objetos (documentos); a catalogação como operação intelectual para descrever os trabalhos documentais e seu conteúdo, assim como a estruturação e gestão de tais descrições para que sejam rastreáveis e detectáveis; a indexação como um recurso analítico de conexões semânticas com o qual se identificam palavras-chave ou descritores de documentos. Por sua vez, desenvolvem-se outras atividades intelectuais para realizar a aquisição, seleção, preservação e a gestão patrimonial.

O segundo âmbito de ação da organização documental relaciona-se com a recuperação, acesso à informação e com o projeto de serviços de informação tais como: referencia, consulta e pesquisa, formação de usuários, empréstimo, assistência, promoção, estimulação, divulgação, fornecimento de espaço e acesso a novas tecnologias. Assim como também outros serviços de extensão tais como os de informação local ou direcionados a grupos populacionais especiais ou excluídos, extensão de serviços a outros sistemas de informação ou instituições das áreas da 
cultura, educação e governo. (QUINTERO CASTRO, 2011)

E. O Sistema Informativo Documental: núcleo duro do programa de pesquisa científica das áreas da informação documental. (Miguel Ángel Rendón. México. Eduardo Mancipe. Colombia)

Nós, junto com o Maestro Eduardo Mancipe da Universidade La Salle de Bogotá, propomos que o Sistema Informativo Documental, formado por Informação, Documento, Usuário, Instituição Informativa Documental, Profissional da Informação Documental, é o núcleo duro do Programa de Pesquisa científica da Ciência da Informação/Documentação e seu objeto de estudo.

Desta forma estudam-se os elementos, processos, atividades, características que regem a dinâmica desse sistema, para conseguir que os "seres informacionais" com certas necessidades, venham ao mundo da informação para satisfazê-las, mediante os documentos que se organizam numa instituição informativa documental. (RENDÓN ROJAS, 2005; MANCIPE FLECHAS, 2011)

Podemos encontrar outras propostas de objeto de estudo da Ciência da Informação: o fenômeno informativo documental, a informação registrada, organizada e disponível para acesso; o ciclo social da informação e o documento; o processo da informação documental; a atividade biblio-informativa; a biblioteca; o documento; a classificação, entre outros. (QUINTERO CASTRO, 2003; MARTÍNEZ RIDER; RENDÓN ROJAS, 2004)

\section{Proposta de Tese Central}

O objetivo da pesquisa não é fazer uma lista do que foi dito até o momento sobre essa questão, nem adicionar uma definição a mais nessa lista. O que se procura é encontrar um denominador comum a toda essa série de propostas, uns princípios mínimos e gerais que permitam chegar a um consenso, ou seja, estamos falando de uma "epistemologia frágil". Ao mesmo, tempo se realizará um trabalho paralelo que consiste em inquirir sobre a origem dessa diversidade de pontos de vista.

InCID: R. Ci. Inf. e Doc., Ribeirão Preto, v. 3, n. 1, p. 3-14, jan./jun. 2012. 
Sobre esta última questão, consideramos que existem vários fatores que determinam a diversidade de pontos de vista sobre o objeto de estudo da disciplina. . Um deles tem a ver com o fato de é um objeto construído, não só como conceito, mas também como objeto mesmo. Toda ciência constrói seus conceitos, incluindo as ciências naturais, mas os referentes desses conceitos "estão lá". Por exemplo, os objetos que foram conceituados como "estrela", "planeta", "pedra", "elemento químico", "ser vivo", "matéria”, existem independentemente do ser humano. A interpretação da realidade se faz sobre objetos dados, no entanto, o objeto de estudo da Ciência da Informação/Documentação é construído em sua totalidade. Desta maneira, a interpretação se faz sobre objetos construídos. Pode-se dizer que há uma intencionalidade sobre intencionalidades.

Outra causa da diversidade de enfoques e propostas sobre o objeto de estudo é a transdisciplinaridade, já que como resultado da evolução de várias ciências, estas convergem para dar origem a uma nova realidade; desta maneira convergem técnicas bibliotecárias, teorias da comunicação, linguística, filosofia, lógica, administração, arquivamento, museologia, computação, entre outras, dando origem a um novo objeto de estudo. Assim, é um objeto construído e ao mesmo tempo novo.

Ao mesmo tempo, é necessário levar em consideração a natureza da Documentação e Estudos da informação como ciência social e humana, o que leva ao surgimento de diferentes interpretações e escolas, característica distintiva deste tipo de ciências. Finalmente, a complexidade do objeto de estudo determina a possibilidade de abordá-lo por diferentes aspectos. Desse modo, pode-se analisar desde uma perspectiva estruturalista, funcionalista, pragmática, social, dinâmica, estática, sistêmica, centrada nos sujeitos, nos objetos, nos processos, etc. Contudo, se for consequente e coerente na linha selecionada desde onde é visto o objeto de estudo, uma análise superior leva a descobrir consequências ou pressupostos que batem outros pontos de vista que num principio não se contemplam. Assim por exemplo, se a análise começa desde uma visão funcionalista, cedo ou tarde terá que se aceitar que essas funções se realizam dentro de umas estruturas (estruturalismo), num ambiente social, que cumprem funções específicas (pragmatismo), etc.

Por todas estas razões, propomos que a existência de diferentes pontos de vista do objeto de estudo da Ciência da Informação é o resultado de uma estruturação de uma mesma realidade, mas com diferente marco interpretativo, a semelhança da psicologia da Gestalt, onde se explica 
que a interpretação, percepção, visão (teoria etimologicamente é "ver") varia de acordo com o enfoque, as tradições, o ambiente do qual começa. Essa Gestalt são as tradições, os préjulgamentos, o horizonte hermenêutico do que fala a hermenêutica filosófica de Gadamer (1997).

São conhecidas as imagens que servem de exemplos na psicologia da Gestalt para mostrar as diferentes percepções que pode haver de una mesma imagem de acordo a estruturação e organização que se faça dessas imagens. A da taça ou dois rostos; a mulher jovem ou velha; ou a do pato ou coelho.

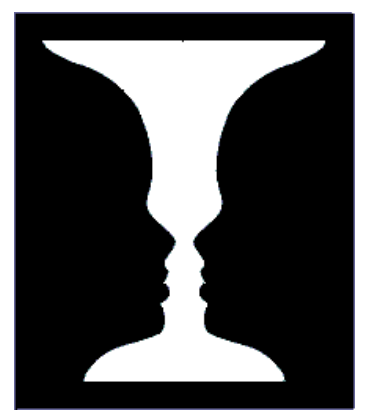

Dois rostos ou uma taça

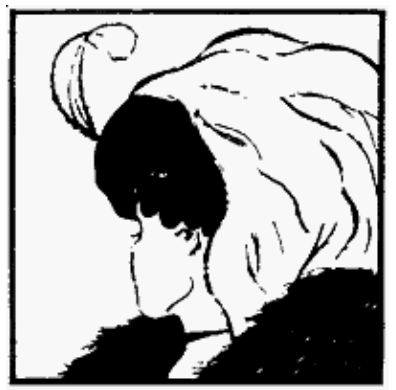

Mulher jovem ou velha

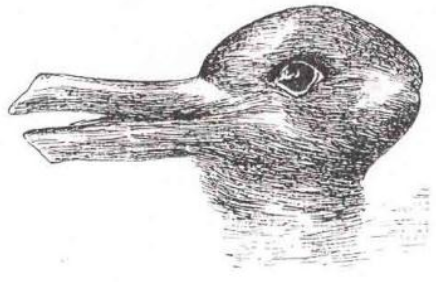

Pato ou coelho

Não é possível discutir quem tem a razão ou a interpretação "correta": quem observa uma taça ou dois rostos; ou no caso das duas imagens restantes, uma mulher jovem ou uma velha, ou um pato ou um coelho. Tudo depende da Gestalt que se integra, mas o que é certo é que existe uma imagem, não é inventada, ilusão, alucinação, sonho, delírio; e com base nessa imagem, se constrói uma interpretação, mas sempre existe a possibilidade de "ver" a outra imagem se colocado em outro quadro de referência, vê-se de outra forma, tem-se outra Gestalt.

Desse modo, a tese que defendemos e queremos demonstrar nesta pesquisa é que, apesar da diversidade de escolas, enfoques e tradições no campo dos estudos da informação documental, é possível chegar a um acordo em general sobre a natureza, objeto de estudo e principais conceitos da disciplina.

Para fundamentar esta tese partimos de um pressuposto ontológico, a existência de uma realidade ontológica, lógica, gnosiológica e epistemologicamente distinta ao sujeito; assim como de pressupostos ontológicos e gnosiológicos: a natureza hermenêutica e dialética dessa realidade 
e por consequência da necessidade de aproximar-se a ela também de uma forma hermenêutica e dialética para conhecê-la.

Desta maneira, a raiz ontológica que justifica a possibilidade do consenso na comunidade científica em estudos da informação é a existência de um campo fenomênico bem determinado que é o campo da informação documental no qual habitam objetos (informação, documentos, unidades, fontes, fundos de informação), sujeitos (usuários, profissionais da informação documental) e processos (geração, coleta, processamento, armazenamento, busca e recuperação, disseminação e uso da informação). Esse campo é essa imagem que pode ser vista com diferentes Gestalt e, portanto vista como diferentes propostas, mas o campo existe.

Cada uma dessas escolas e enfoques dentro da Ciência da Informação/Documentação responde a uma Gestalt determinada, é induzida por uma realidade objetiva. Se for respeitada essa realidade então esse ponto de vista não é inventado, mesmo que tampouco possa pretender ser o único e verdadeiro. E ao mesmo tempo, mesmo que se tenha uma percepção da disciplina enquanto seu objeto de estudo e estrutura teórica, produto da Gestalt que se tem, sempre existe a possibilidade de mudar de Gestalt ao descobrir que essa percepção pode organizar-se de outra maneira.

Uma análise profunda e coerente das diferentes interpretações leva a convergências nos pressupostos, à descoberta de complementações ou consequências que seguem dessas interpretações já que compreendido o objeto de estudo como um todo, um ponto particular tem relações com o todo.

O objeto de estudo da Ciência da Informação/Documentação é complexo e pode ser denominado genericamente de maneira tentativa, fenômeno informativo documental em sua interpretação estática ou ciclo da informação documental em sua versão dinâmica. Esse objeto de estudo pode ser visto a partir da perspectiva da comunicação e intermediação (López Yepes, Delgado y Pirela); a partir da organização (Quintero Castro, Ortega); ou a partir do sistêmico (Rendón Rojas, Mancipe Flechas).

Assim, além da realidade informativa documental ser construída a posteriori pelo sujeito, é nova e complexa, desde o ponto da hermenêutica, os sujeitos constroem seus sentidos o que vem a complicar ainda mais o panorama. Ao encontrarmos com uma diversidade de 
interpretações dos fenômenos informativo-documentais devemos lembrar que cada pesquisador se encontra dentro de, na terminologia de Gadamer (1997), um horizonte hermenêutico da onde vê e interpreta a realidade graças aos pré-julgamentos e tradições que seu contexto lhe oferece. Um contexto particular de política, cultura e tradições de pesquisa, conhecimentos prévios, crenças, valores, etc. Graças a esses pré-julgamentos e tradições é possível chegar à précompreensão e depois à compreensão. Posteriormente através do diálogo e reinterpretação, se pretende ampliar o horizonte hermenêutico de cada participante para coloca-los em contato, e desta forma chegar a uma pós-compreensão.

Entretanto, essa construção hermenêutica de sentidos deve ser complementada com uma visão dialética da realidade e de modo a conhecer essa realidade. Concebemos à dialética como a forma de ver e compreender a realidade (que por sua vez é dialética) constituída por oposições, mas sem absolutizar algum deles, pois que cada um dos opostos tem sua própria presença e existência; enquanto que ao mesmo tempo exigem a existência de seu oposto para existir.

Conceber a realidade como uma tensão de opostos, sem eliminar algum deles, nos permite ter uma compreensão mais completa da realidade sem cair no absolutismo dogmático, ou no relativismo cético. Desta maneira trata-se de uma dialética mais pré-moderna de estilo présocrático a qual busca a convivência dos opostos que vivem precisamente de sua tensão ou na tensão; e não do tipo hegeliano-marxista que busca sua destruição mútua e a superação dos opostos numa síntese superior. (BEUCHOT, 2009).

\section{Categorias da Ciência da Informação}

Como já foi mencionada, a pesquisa que se realiza também tem como um de seus objetivos, analisar e esclarecer os principais conceitos e categorias da Ciência da Informação. Até então, podemos dizer que esta fase de análise do aparato conceitual da Ciência da Informação se encontra em processo de construção. A este respeito, é apenas possível indicar que desde nosso ponto de vista, podemos encontrar conceitos e categorias de acordo com seu referente. Desta maneira temos conceitos relativos a:

InCID: R. Ci. Inf. e Doc., Ribeirão Preto, v. 3, n. 1, p. 3-14, jan./jun. 2012. 


\section{A. Sujeitos}

Tais como "usuário", "profissional da informação", "autor", "editor", "comunidade", entre outros.

Já em outros trabalhos mencionei como se concebem alguns deles. Por exemplo:

Usuário: "Ser informacional" (para existir constrói, consome informação) que possui uma necessidade de informação e exige ou pode exigir satisfazê-la em uma unidade de informação. (RENDÓN ROJAS, 2005)

Profissional da informação: Demiurgo, que com sua atividade do caos informacional constrói a ordem documental. (RENDÓN ROJAS; DELGADO HERRERA, 2010) Sujeito ativo no processo da comunicação documental. (RENDÓN ROJAS, 2005).

\section{B. Objetos}

Entre este tipo de conceitos que se referem a objetos encontramos, por exemplo, "informação", "documento", "fonte", "fundo", "linguagem documental", "unidade de informação", "tecnologia da informação", entre outros.

Do nosso ponto de vista, temos a informação como ente ideal (abstrato), construído baseado em características secundárias dos signos. (RENDÓN ROJAS, 2005).

O documento é a objetivação, consciente e intencionada da informação, mais o menos duradoura, e cuja desobjetivação conduz novamente à informação; além de que um documento nesta área do conhecimento é o resultado de ser controlado pelo profissional da informação documental. (RENDÓN ROJAS, 2005)

\section{Processos}

Finalmente dentro de conceitos que tem a ver com processos, encontramos "geração da informação", "coleta da informação", "processamento da informação", "armazenamento da informação", "busca e recuperação da informação", "disseminação da informação", "uso da informação"; "leitura", "educação ou formação de usuários" (Alfabetização informativa), 
"políticas de informação", "avaliação e desenvolvimento de coletas", "valorização de documentos", entre outros.

Podemos dizer que no aparato teórico conceitual da Ciência da Informação acontece o mesmo que na análise de seu objeto de estudo. Independentemente da diversidade terminológica, o significado pode ter variações nas interpretações, devido a como se tem indicado a complexidade do fenômeno estudado.

No entanto, é possível chegar ao consenso e à compreensão devido à existência desse referente externo do qual foi dito; desta maneira os fenômenos que "habitam" o mundo informativo documental são construídos, mas não subjetivos.

\section{Referencias}

BEUCHOT, Mauricio. Respuesta a "Los limites de la hermenéutica analógica". Multidisciplina: Revista electrónica de la Facultad de Estudios Superiores Acatlán, Naucalpan, n. 3, 2009. p. 107-109. Disponível em: 〈http://www.acatlan.unam.mx/multidisciplina/21/ >. Acesso em: jun. 2012.

DELGADO, Francys; PIRELA Johann. Los procesos de mediación del conocimiento como elementos integradores-unificadores del discurso epistemológico de las ciencias de la información. Universidad de Zulia. Venezuela. In: SEMINARIO ESPECIALIZADO SOBRE EPISTEMOLOGÍA DE LA BIBLIOTECOLOGÍA Y ESTUDIOS DE LA INFORMACIÓN, 2011, México. Documento inédito. México: CUIB-UNAM, 2011.

GADAMER, Hans-George. Verdad y método I: fundamentos de una hermenéutica filosófica. Salamanca: Sígueme, 1997.

LÓPEZ YEPES, José. Una teoría comunicativa de la biblioteconomía/documentación/ciencia de la información. Universidad complutense de Madrid. In: SEMINARIO ESPECIALIZADO SOBRE EPISTEMOLOGÍA DE LA BIBLIOTECOLOGÍA Y ESTUDIOS DE LA INFORMACIÓN, 2011, México. Documento inédito. México: CUIB-UNAM, 2011.

MANCIPE FLECHAS, Eduardo. Los sistemas de información documental [sid] como núcleo común de las disciplinas aplicadas en el campo de la ciencia de la información. Universidad de la salle. Bogotá. In: SEMINARIO ESPECIALIZADO SOBRE EPISTEMOLOGÍA DE LA BIBLIOTECOLOGÍA Y ESTUDIOS DE LA INFORMACIÓN, 2011, México. Documento inédito. México: CUIB-UNAM, 2011. 
MARTÍNEZ RÍDER, Rosa María; RENDÓN ROJAS, Miguel Angel. Algunas propuestas latinoamericanas de objetos de estudio para la investigación bibliotecológica. Revista Ineramericana de Bibliotecología, Medellín, v. 17, n. 1, p. 13-44, 2004.

ORTEGA, Cristina. Objeto y concepto de la disciplina. Belo Horizonte, Brasil. In: SEMINARIO ESPECIALIZADO SOBRE EPISTEMOLOGÍA DE LA BIBLIOTECOLOGÍA Y ESTUDIOS DE LA INFORMACIÓN, 2011, México. Documento inédito. México: CUIB-UNAM, 2011.

QUINTERO CASTRO, Nathalia. Bibliotecología, documentación y ciencia de la información: hacia la identificación de un núcleo común y varios objetos de investigación. Universidad de Antioquia, Escuela Interamericana de Bibliotecología. In: SEMINARIO ESPECIALIZADO SOBRE EPISTEMOLOGÍA DE LA BIBLIOTECOLOGÍA Y ESTUDIOS DE LA INFORMACIÓN, 2011, México. Documento inédito. México: CUIB-UNAM, 2011.

QUINTERO CASTRO, Nathalia et al. Objeto de estudio para una bibliotecología orientada al contexto sociocultural colombiano: propuesta abierta al debate. Revista Ineramericana de Bibliotecología, Medellín, v. 26, n. 2, Separata, 2011.

RENDÓN-ROJAS, Miguel Ángel. Bases teóricas y filosóficas de la bibliotecología. México: CUIB-UNAM, 2005.

RENDÓN-ROJAS Miguel Ángel. La ciencia de la información en el contexto de las ciencias sociales y humanas: ontología, epistemología, metodología e interdisciplina. Datagramazero revista de ciência da informação, v. 9, n. 4, ago. 2008. Disponível em:

<http://www.datagramazero.org.br/ago08/F_I_art.htm>. Acesso em: jun. 2012.

RENDÓN-ROJAS, Miguel Ángel; HERRERA DELGADO, Lizbeth Berenice. El profesional de la información documental. Eidos-noumeno-identidad versus-skia-fenómeno-imagen. Revista Mexicana de Ciencias de la Información, v. 1, n. 2, p. 40-52, 2010.

SERRAI, Alfredo. Biblioteconomía come scienza: introduzioneai problema e alla metodología. Firenze, Italia, 1982.

Artigo submetido em: 01 jun. 2012

Artigo aceito em: 16 jun. 2012

InCID: R. Ci. Inf. e Doc., Ribeirão Preto, v. 3, n. 1, p. 3-14, jan./jun. 2012. 